ворной компетентности // Инновации и образование. 2014. № 4. C. 106-111.

12. Рехтина Н.В. Организация и проведение переговоров в случаях осложнения оперативной обстановки или возникновения чрезвычайных обстоятельств в учреждениях уголовно исполнительной системы: учеб.-метод. пособие. М.: ФКУ НИИТ ФСИН России, 2014. 136 с.

13. Лобачева Л.П. Психологическое обеспечение переговорной деятельности сотрудников УИС в ситуации захвата заложников // Групповые неповиновения и массовые беспорядки в учреждениях УИС: сб. мат-лов круглого стола (30 ноября 2017 г., г. Москва)
/ под общ. ред. д.э.н., профессора С.В. Гарника. М.: ФКУ НИИИТ ФСИН России, 2018. С. 244-249.

14. Тарасова С.А. Пенитенциарная психология: учеб. пособие. Самара: СЮИ ФСИН России, 2016. 174 с.

15. Дмитриев Ю.А., Фролова А.А. Активные методы обучения в подготовке педагогов: деловая игра и тренинг // Наука, образование, культура. 2017. № 2. C. $84-96$.

16. Фишман И.С., Голуб Г.Б. Формирующая оценка образовательных результатов учащихся: Методическое пособие. Самара: Издательство «Учебная литература», 2007. 244 c.

\title{
PEDAGOGICAL TECHNOLOGY OF STUDENTS' NEGOTIATION IN EMERGENCIES COMPETENCE DEVELOPMENT AT PENAL SYSTEM INSTITUTIONS
}

(C) 2019

Tarasova Svetlana Aleksandrovna, candidate of psychological sciences, associate professor of Penitentiary Psychology and Pedagogy Department

Oshchepkova Olga Vladimirovna, doctor of pedagogical sciences,

professor of Penitentiary Psychology and Pedagogy Department

Samara Law Institute of the Federal Penitentiary Service of Russia (Samara, Russian Federation)

Abstract. The paper is devoted to the problem of professional and psychological training of employees of the penal system at university. The authors have developed a technology of teaching negotiations to students on the basis of competence-based approach while studying psychological disciplines. The authors define the concept of «a negotiation competence of the penal system employee», which is understood as a professional and personal readiness to negotiate with convicts in emergency conditions. The negotiation competence is considered in the context of conflicts resolution in case of group disobedience and mass riots at institutions of the penal system. The structure of the negotiation competence: motivational value, cognitive, efficient, practical and reflective components, reflecting the nature of the negotiation activity. The technology of negotiation competence development consists of the target, substantive, procedural, criterial and assessment units. The paper describes the content of training on the basis of organizational, communicative, ethical, technological, information components of the competence. The list of the planned educational results is given. The authors consider a procedural part of negotiation skills development, reflecting the content and sequence of stages. Methodical techniques used for training are described, examples of tasks are given. A business game is presented as an interactive form of training at the practical stage. The ways of checking if the educational results are developed with the help of the current and final control are discussed.

Keywords: professional and psychological training; pedagogical technology; negotiation competence; negotiation process; criminal-executive system; prison staff; convicts; extraordinary circumstances; content of training; teaching methods; business games.

\section{ВЛИЯНИЕ ПРОЕКТНОГО ОБУЧЕНИЯ СТУДЕНТОВ-БАКАЛАВРОВ НА ВЫБОР НАПРАВЛЕНИЯ ПОДГОТОВКИ В МАГИСТРАТУРЕ}

\author{
Хаертдинова Альфира Анасовна, кандидат экономических наук, \\ доцент кафедры инноватики в химической технологии \\ Казанский национальный исследовательский технологический университет \\ (2. Казань, Российская Федераичия)
}

\footnotetext{
Аннотация. В статье представлены результаты выявленных внутренних противоречий обучения на уровнях бакалавриата и магистратуры и факторы, повлиявшие на выбор выпускниками бакалавриата направленности обучения на ступени магистратуры на примере студентов, обучающихся в Казанском национальном исследовательском технологическом университете (КНИТУ) на кафедре инноватики в химической технологии (ИХТ). Особенностью подготовки бакалавров на кафедре ИХТ стало внедрение технологии проектного обучения в образовательные программы кафедры в рамках стратегии развития университета. Внедрение данной технологии сказалось на степени подготовки студентов, обучающихся на кафедре, поспособствовав раскрытию умственных и творческих способностей студентов, реализации личностных лидерских или исполнительских качеств, применению полученных теоретических знаний для решения проблем, связанных с внедрением инновационных проектов, оценкой их эффективности и результативности, на практических инновационных проектах. Применение проектной технологии обучения позволяет подготовить студентов не только
} 
к способности самостоятельно развиваться в реальном секторе экономики, но и дать оценку полученных в ходе обучения на ступени бакалавриата знаний, а также оценить недостатки и пробелы в знаниях в области отдельных дисциплин за весь период обучения. Такая осознанная самооценка необходима для принятия решения по продолжению образования в магистратуре в том направлении, где выпускники ощущают наиболее острую необходимость углубить профессиональное обучение.

Ключевые слова: проектная технология обучения; Болонская декларация; образовательная программа; междисциплинарное обучение; профессиональные компетенции; учебные планы; инноватика; управление проектами; бакалавриат; магистратура; инновационный проект; химические технологии.

Основная задача высших учебных заведений Российской Федерации - подготовка высококвалифицированных кадров для современной экономики [1]. В настоящее время работодателю уже недостаточно получить дипломированного специалиста: на предприятиях хотят видеть молодых, креативных работников, умеющих мыслить нестандартно, инновационно и способных адекватно оценивать результаты проделанной работы [2, с. 374]. Особенно важны эти качества, если молодой специалист хочет реализовать себя как индивидуальный предприниматель или связать свою деятельность с сектором малого бизнеса или малого предпринимательства. Подготовка профессионалов такого уровня требует особого подхода к образовательному процессу и поиску новых методов обучения.

В мировых университетах давно используется и популярна проектная технология обучения. Опыт постепенно перенимается и приходит в российскую систему высшего образования. Данная педагогическая технология находит все большее применение на ступени бакалавриата. Многие высшие учебные заведения России внедряют образовательные программы с элементами проектного обучения. Новые технологии направлены на значительное повышение качества образования и подготовку конкурентоспособных выпускников.

В России подготовка бакалавров по направлению «Инноватика» традиционно носит междисциплинарный характер ФГОС [3]. Практика подготовки в КНИТУ не является исключением. Студенты получают знания сразу в нескольких направлениях. Обучение начинается с основ химии, физики, материаловедения. Далее студенты углубляются в изучение дисциплин по химической технологии: промышленным технологиям и инновациям, основам полимерной химии, механике и технологии. Дисциплины, связанные с инновационным менеджментом, занимают существенную долю в программе: теоретическая инноватика, инновационное развитие химических технологий, управление инновационной деятельностью, управление инновационными проектами и др. [4]. Начиная с третьего семестра, студенты изучают глубоко дисциплины проектного менеджмента: экономика инновационного предприятия, стратегический менеджмент в инновационных организациях, анализ финансово-хозяйственной деятельности предприятия, экономическая оценка инвестиций и др.

Как правило, после окончания обучения на бакалавриате по направлению «Инноватика» студенты поступали в магистратуру, не меняя направления подготовки, для получения более углубленных знаний. Однако начиная с 2015 года на кафедре инноватики в химической технологии для бакалавриата был введен качественно новый уровень подготовки студентов - проектное обучение. Это привело к очень большой диверсификации и осознанности выбора направлений дальнейшего обучения в магистратуре.

Условно период реализации проекта можно разбить на несколько этапов: от выбора темы до разработки и организации плана проекта и до анализа и оценки результатов инновационного проекта. Исполнение проекта в общей сложности занимает почти два года. По завершении проекта студенты имеют технико-экономическое обоснование по производству полимерного инновационного продукта.

В настоящее время разработка технико-экономического обоснования проекта начинается с пятого семестра (третий курс) и продолжается до окончания всего образовательного процесса. В течение двух лет студенты занимаются индивидуальными проектами. Полностью завершенный проект создания инновационного производства представляет собой готовую бакалаврскую работу. Схема подготовки студентов к разработке собственного инновационного проекта тесно связана с изучением специальных дисциплин. Каждая такая дисциплина помогает студенту отработать отдельную часть проекта. Так, например, дисциплины химико-технологической направленности становятся определяющими при решении вопроса подбора технологического оборудования и схемы процесса. Для решения и освещения в проекте вопросов менеджмента и маркетинга служат дисциплины: управление проектами, экономическая оценка инвестиций и бизнес-планирование, логистика, стратегический менеджмент, маркетинг и налогообложение. Студент разрабатывает разделы проекта по мере освоения дисциплин по учебному плану в период обучения на последних двух курсах. Таким образом, образование строится на сочетании дисциплин трех направлений - это инновационный менеджмент, химические технологии и экономика. Учитывая специфику обучения в технологическом университете (в институте полимеров), инновационные проекты связаны с производством полимерной продукции. Студенты, вне зависимости от того, каким проектом они занимаются (производство биоразлагаемых пищевых контейнеров, или травмобезопасных перчаток, или люминесцентной тротуарной плитки и проч.) получают такие компетенции, которыми сложно овладеть при изучении учебного пособия или лекций. Это навыки практического применения знаний, освоенных в рамках изучаемых дисциплин и опыта, полученного при оценке эффективности проекта и возможных рисков при его реализации с учетом динамики изменений, происходящих в экономике.

Программа магистратуры, в соответствии с Болонской декларацией, предусматривает преемственность дисциплин [5; 2], дающих возможность продолжить обучение по направлению подготовки «Инноватика» или родственного ему по содержанию. 
Однако, как показал наш опыт, многие бакалавры после введения проектного обучения осознанно делают выбор не в пользу соблюдения преемственности [6, с. 98]. Для изучения факторов, обусловивших смену направления продолжения образования в магистратуре, нами было проведено исследование. Изучалась структура и динамика поступления в магистратуру выпускников бакалавриата, которые обучались на программе до внедрения проектного обучения и после.

По результатам исследования было выявлено, что из 34 студентов-инноватиков, завершивших освоение программы бакалавриата в 2018 году, только 3 человека $(8,8 \%)$ продолжили обучение в магистратуре по направлению «Инноватика», 22 выпускника $(64,7 \%)$ продолжили обучение в магистратуре, но остановили свой выбор на инженерно-технологическом направлении, 6 человек $(17,6 \%)$ выбрали инновационное предпринимательство. Таким образом, траектория обучения бакалавриат $\rightarrow$ магистратура складывается так, что бакалавры инноватики отдают предпочтение магистратуре технологического образования или естественнонаучного направления. Ситуация 2017 года демонстрирует примерно такие же соотношения: $10,1 \%, 63,2 \%$ и $26,7 \%$ соответственно.

Одновременно исследование поступивших в магистратуру по направлению «Инноватика» выявило, что в магистратуру приходят бакалавры с техническим и гуманитарным образованием для получения навыков инновационного проектирования.

Большое влияние на выбор бакалаврами направления магистратуры оказали те предметы и разделы проекта, которые вызвали живой интерес в процессе выполнения проекта и по которым появилось осознание недостатка знаний. Для углубления знаний в интересующей области бакалавры теперь продолжают образование в магистратуре по одному из трех направлений: химические технологии, инновационный менеджмент или экономика.

В результате исследований получены также предложения и рекомендации студентов по дальнейшему совершенствованию учебных планов бакалавров по направлению «Инноватика». Третья часть обучавшихся отметили, что в процессе подготовки изучение дисциплин, связанных с управлением проектами, было наиболее полезным, около 10\% выпускников считают, что необходимо усилить обучение именно в этой сфере. Этим объясняется то, что большая часть студентов приняла решение продолжить образование и получить более глубокие знания на технологическом направлении по магистерской программе профессиональной подготовки.

Наиболее интересными были предложения в части возможного раскрытия личного потенциала обучающихся. Более $50 \%$ опрошенных предложили включить в систему подготовки специалистов для инновационной сферы программу, ориентированную на различные уровни управления, чтобы у студентов была возможность реализовать свой личностный потенциал - это могут быть врожденные личные свойства или качества характера. Такая идея родилась у студентов не на пустом месте. Во время прохождения преддипломной практики на одном из предприятий г. Казани студенты были распределены по производственным цехам группами. Известно, что «про- изводственная практика направлена на развитие прикладных профессиональных компетенций студентов» [7, с. 145]. Именно такая форма знакомства с реальной производственной средой позволяет студентам в относительно короткие сроки адаптироваться к производственной обстановке, лучше узнать условия труда, самим почувствовать, что представляют из себя «Правила внутреннего распорядка предприятия» и др. Работая в небольших группах, студентам удалось решить непростые проблемы оптимизации работы в цехах. Хорошая теоретическая подготовка, знание теоретических основ инновационных составляющих, смелые взгляды, с учетом изученного зарубежного опыта и современной отечественной литературы, позволили студентам поновому оценить все процессы, происходящие на производстве, и внести новые идеи в совершенствование технологического процесса и внутренней организации работы на участках и в производственных цехах. В ходе практики проявились личностные качества студентов. Российские исследователи рассматривают факторы, влияющие на развитие творческих способностей студентов, выделяя несколько очевидных категорий.

Первая категория - так называемые «креативщики», небольшая группа креативно мыслящих, активных, смелых студентов, способных выдавать нестандартные рекомендации по решению технических задач и профессионально представить их руководству [8, c. 255].

Вторая категория - «аналитики», студенты, способные анализировать, выявлять недостатки, нарушения технологического регламента. По сути, это развитая, с широким кругозором группа студентов, с большими возможностями, которая незаменима в любой инновационной деятельности [9, с. 94].

Третья категория - «исполнители», студенты, способные написать отчет, подготовить презентацию, грамотно выполнить поставленные задачи, работать эффективно и обеспечивать реализацию основных функций отдела, участка, цеха [10, с. 105].

Инициативы студентов сводились к предложению по выявлению и развитию психологического профиля обучающегося: так как для инновационной сферы развития требуются специалисты разных уровней, то и появление в учебном процессе программ, ориентированных на развитие личностных качеств, было бы предпочтительно.

В целом подготовка студентов по программе проектного обучения на кафедре инноватики в химической технологии способствует тому, чтобы студенты приобрели целый ряд конкурентных преимуществ.

Изучение маркетинга, менеджмента и налогообложения проходит в неразрывной связи с изучением основ полимерной химии и электротехники. Это приводит к тому, что «выпускники кафедры ИХТ крайне разносторонние специалисты, прекрасно разбирающиеся как в экономической, так и в производственной составляющей инновационного бизнеса в химической сфере, понимают процессы разработки и внедрения инноваций от момента зарождения новых идей до стадии коммерциализации» [11, с. 1001].

Кроме того, студенты-инноватики имеют прекрасные возможности активно применять теоретические знания на практике, разрабатывая собственные 
бизнес-планы и проходя производственную и преддипломную практики на производственных предприятиях Республики Татарстан.

\section{Выводы}

Проводимая в системе образования уже более 10 лет модернизация, в связи с переходом России на Болонскую систему, свидетельствует о некотором несовпадении с «основным спектром развертывания Болонского процесса» [6, с. 104]. В частности, это касается введения двухциклового обучения: достепенного (бакалавриат) и степенного (магистратура), предполагающего продолжение обучения по одному и тому же направлению. Магистратура - это более широкие возможности, чем простая преемственность. Это шанс не только продлить обучение, но и выбрать новый профиль, расширить кругозор, знания и профессионализм. Многие выпускники-бакалавры выбирают именно данную траекторию.

\section{Список литературы:}

1. Федеральный закон «Об образовании в Российской Федерации» от 29.12.2012 г. № 273-Ф3 [Электронный pecypc] // https://consultant.ru/document/ cons_doc_LAW_140174.

2. Сайдаматов Ф.Р. Развитие творческих способностей студентов в процессе профессиональной подготовки // Молодой ученый. 2012. № 8. С. 374-375.

3. Приказ Министерства образования и науки РФ от 30.10.2014 г. № 1415 «Об утверждении федерального государственного образовательного стандарта высшего образования по направлению подготовки «Инноватика» [Электронный ресурс] // https://base. garant.ru/70812446.

4. Стародубова А.А., Бурылина Г.Г. Оценка эффективности программ по предпринимательству для магистрантов инженерных специальностей // Материалы международного научного форума «Образование. Наука. Культура»: сб. науч. ст. / под общ. ред. проф. Б.В. Илькевича; отв. ред. Н.В. Осипова. Гжель: Гжельский государственный университет, 2019. C. $223-225$.

\section{THE IMPACT OF PROJECT STUDIES WHILE TEACHING UNDERGRADUATES ON THE CHOICE OF A MASTER'S PROGRAM}

(C) 2019
5. Болонская декларация. Зона европейского высшего образования. Совместное заявление европейских министров образования, г. Болонья, 19 июня 1999 г. [Электронный ресурс] // http://docs.cntd.ru/ document/902071713.

6. Иванова В.И. Болонский процесс и российское высшее образование // Педагогика. 2006. № 1. С. 97105.

7. Маляшова А.Ю., Исхакова Д.Д., Султанова Д.Ш. Практика погружения в реальный бизнес как механизм развития предпринимательских компетенций у студентов инженерных специальностей // Вестник Университета талантов: научно-практический журнал. 2018. № 3-4. С. 141-147.

8. Куприянычева Н.И., Куприянычева Э.Б., Сагдеева Г.С. Влияние мотивации на повышение эффективности учебного процесса в техническом вузе национальном исследовательском университете // Вестник Казан. нац. исслед. технол. ун-та. 2012. № 7. C. 254-257.

9. Султанова Д.Ш., Исхакова Д.Д., Маляшова А.Ю. Развитие предпринимательских компетенций у студентов инженерных специальностей // Вестник Университета талантов: научно-практический журнал. 2017. № 2. C. 93-95.

10. Маляшова А.Ю., Исхакова Д.Д., Султанова Д.Ш. Формирование предпринимательских компетенций у студентов посредством практики погружения в реальный бизнес // Интегративная подготовка линейных инженеров для повышения производительности труда предприятий нефтегазохимической отрасли: сб. докл. и науч. ст. междунар. сетевой науч.-практ. конф. «Синергия - 2018»: в 2-х ч. Ч. 1. Казань: Изд-во «Бронто», 2018. С. 103-111.

11. Маляшова А.Ю., Исхакова Д.Д., Султанова Д.Ш., Ярошевская Х.М. Роль родителя в воспитании предпринимательских качеств у школьника // Экономика и предпринимательство. 2018. № 3 (92). C. 1002-1004.

\section{Khaertdinova Alfira Anasovna, candidate of economical sciences,} associate professor of Innovation in Chemical Technology Department Kazan National Research Technological University (Kazan, Russian Federation)

Abstract. The paper presents the results of the identified internal contradictions of MA and BA courses and the facts that influenced the choice of a master's program on the example of students studying at Kazan National Research Technological University, at Innovation in Chemical Technology Department. One of the features of teaching bachelors at Innovation in Chemical Technology Department was the introduction of project training in the educational programs of the department as part of the university development strategy. The introduction of the project training method affected the degree of teaching students of the department. Students' project activities are aimed at revealing their mental and creative abilities, implementing personal leadership or performing skills, applying theoretical knowledge gained to solve problems related to the implementation of innovative projects, assessing their effectiveness and efficiency in practical innovative projects. This type of training allows to teach students to independently develop in the real sector of the economy, as well as to evaluate the knowledge gained during BA course training, as well as to assess the shortcomings and gaps in the field of individual disciplines for the entire period of study. Such a conscious self-esteem is necessary to make a decision on continuing education at a MA course.

Keywords: Bologna Declaration; educational program; interdisciplinary training; professional competencies; educational plans; innovation project management; undergraduate studies; MA course; project activities; innovative project; chemical technology. 